\title{
CONTAMINATION AND RESTERILIZATION OF THE BAIN CIRCUIT
}

\author{
A.C. Enright, R.L. Moore, and F.L. Parney
}

OVER A NUMBER OF YEARS, concern has developed for the role played by anaesthetic equipment in the transmission of infection to patients undergoing general anaesthesia. $^{1-5}$ This concern has led to the introduction and use of plastic disposable anaesthetic circuits., ${ }^{1, i}$ Many institutions have now resorted to reusing these circuits, with or without sterilization, because of the cost involved. ${ }^{8}$ This study was undertaken to determine the extent of contamination of the Bain circuit during use and the practicality of resterilization.

\section{METHODS}

Fifty patients ranging in age from 2 to 83 years, were chosen at random from the operating lists of the Alberta Children's Hospital and the Calgary General Hospital. Each patient, or parent in the case of the children, was interviewed to determine a history of infection within the recent past. In addition, each patient was examined for obvious and occult infection. There was no standardization of premedication or anaesthetic techniques.

One Bain circuit (Respiratory Care Inc., Arlington Heights, Ill.) was used for each patient. All circuits were from the same lot. Immediately following the conclusion of each anaesthetic, cultures were taken with swabs from inside the circuit at $1,7,13$, and $19 \mathrm{~cm}$ from the patient end. Each swab was pre-moistened and rotated fully within the tube over the $6 \mathrm{~cm}$ length. The complete surface of a blood agar plate was streaked with each swab and the swab was then cultured in $12 \mathrm{mls}$ of fluid thioglycollate testing medium (BBL, Cockeysville, Md.). The cultures were examined for growth after 24 and 48 hours of incubation at $37^{\circ} \mathrm{C}$. Standard bacteriological methods were used for the identification of organisms in positive cultures.

Thirty-three Bain circuits were inoculated with Staphylococcus aureus (phage type 3A, Laboratory Centre for Disease Control, Ottawa, Ont.) by dipping the circuits into actively growing cultures with a density of about $2 \times 10^{8}$ cells $/ \mathrm{ml}$. The circuits were then repackaged and sealed. Twenty-five of the circuits were processed in an ethylene oxide sterilizer for 5.5 hours at $100^{\circ} \mathrm{F}, 10$ p.s.i., 80 per cent relative humidity and 12 per cent ethylene oxide. Six of the circuits were processed in an automatic sterilizer using activated 2 per cent glutaraldehyde as its sterilizing agent (Cidematic, Arbrook Inc., Peterborough, Ont.). The two remaining circuits were used as positive controls. After treatment, a 4-inch section of each tube was incubated at $30^{\circ} \mathrm{C}$ for 30 days in $40 \mathrm{ml}$ of fluid thioglycollate medium.

The departments of Anaesthesia and Laboratories, Foothills Hospital, Calgary, Alberta.

545

Canad. Anaesth. Soc. J., vol. 23, no. 5, September 1976 


\section{Results}

Of 50 Bain circuits examined immediately following their use on patients, only four were found to have become contaminated. The data for these patients are summarized in Table I. No correlations were observed between patient ages, type of surgery or the length of time the circuit was used and the occurrence of contamination. The organisms isolated represent the expected normal human fora. Their numbers were large enough that the positive cultures were clearly evident within 24 hours.

Bain circuits seeded with Staphylococcus aureus were used to examine the ease with which they might be resterilized. Ethylene oxide sterilization proved to be effective with all of the 25 circuits tested, while two of six circuits treated in a Cidematic sterilizer remained non-sterile.

The possibility of ethylene oxide sterilization producing unwanted alterations in the Bain circuit was examined by subjecting ten circuits to five consecutive cycles of sterilization as described in the Methods section. No physical changes could be observed by visual examination or by the Pethick pressure test." Tests for pyrogens by rabbit injection (United States Pharmacopeia, Vol. 18) also remained negative after this procedure.

\section{Discussion}

There is no doubt that, over the years, anaesthetic equipment has been responsible for outbreaks of nosocomial infection. ${ }^{10-12}$ Although the organisms isolated from contaminated disposable circuits in this study cannot be considered serious pathogens, a contamination rate of 8 per cent is far too high to permit consideration of re-use of these circuits on the susceptible patient without resterilization.

There has been much interest in the various methods of sterilizing anaesthetic equipment ${ }^{1:-1 i}$. Not all methods are suitable for sterilizing Bain circuits. For example, steam sterilization will cause the circuits to melt. The two methods which we chose to examine were ethylene oxide and activated gluteraldehyde. In our hands, only ethylene oxide was satisfactory. The use of ethylene oxide, however, has been disputed, ${ }^{14-21}$ particularly for materials previously sterilized by gamma irradiation. ${ }^{-2.23}$ This does not pose a problem in this investigation, however, since the circuits were originally sterilized by ethylene oxide ( $M$. Foley, personal communication). In addition, neither physical damage to the circuits nor the presence of pyrogens could be detected after consecutive sterilization cycles with ethylene oxide.

From this study, we conclude that ethylene oxide sterilization is a safe method for the resterilization of the Bain circuit. However, it is recognized that there is an upper limit to the number of times the circuits could be resterilized without damage.

By employing this procedure, patients would continue to enjoy maximum safety at lower cost and a small step toward reducing the quantity of non-biodegradable materials in our environment will have been accomplished. 
ENRIGHT, et al.: RESTERILIZATION OF BAIN CIRCUIT

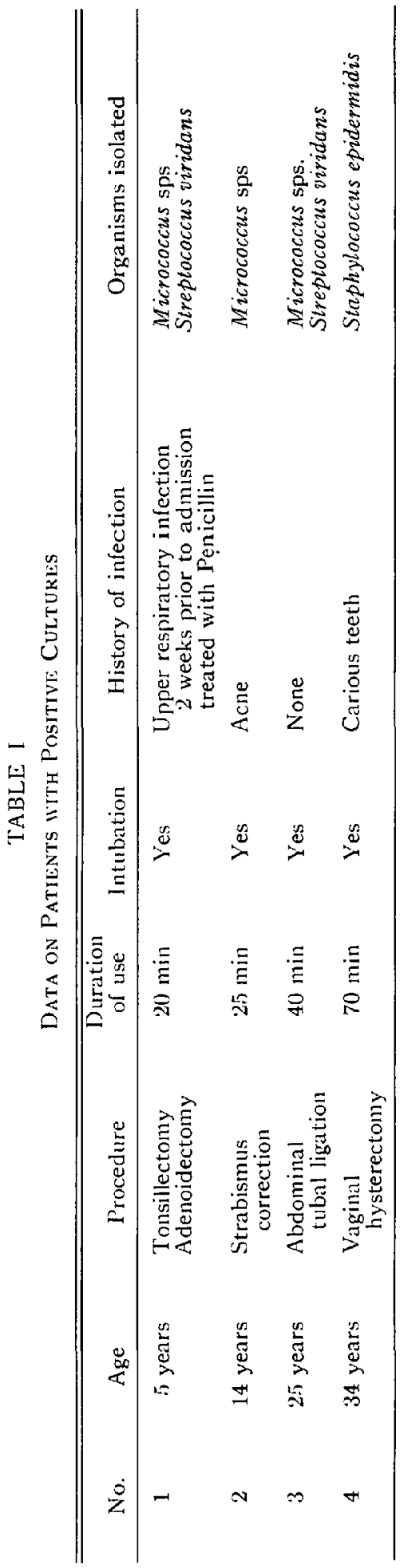




\section{SUMMARY}

Fifty Bain circuits were tested for contamination following single patient use. A contamination rate of 8 per cent was found. Two methods of resterilization were examined. Sterilization by activated glutaraldehyde proved unsatisfactory, while ethylene oxide sterilization was found to be an effective method which produced no detectable adverse physical or chemical alterations of the circuits.

\section{RÉSUMÉ}

Une recherche de contamination effectuée sur 50 circuits Bain après usage chez un seul patient, a mis en évidence une contamination bactérienne dans quatre cas.

Deux des six circuits contaminés ont continué à donner des cultures positives après tentative de les stériliser au moyen de glutaraldehyde activée.

Vingt cinq circuits contaminés ont tous été démontrés bien stériles après stérilisation à l'oxyde d'éthylène.

Dix circuits stérilisés cinq fois de suite à l'oxyde d'éthylène sont demeurés mécaniquement inchangés.

Les auteurs discutent de la restérilisation de l'équipement “à usage unique” et concluent que l'oxyde d'éthylène est une méthode satisfaisante de restérilisation des circuits Bain.

\section{ACKNOWLEDGMENTS}

The authors wish to thank the following for their assistance in completing this project: Foothills Hospital Research and Development Committee; Calgary General Hospital; Alberta Children's Hospital; Dr. A.M. Tulloch; Dr. W.R. Hesson; Mrs. Cara Snider; Mrs. Gloria Dickson and Mrs. Joan Haden.

\section{REFERENCES}

1. Roвerts, R.B. The anaesthetist, cross-infection and sterilization. Techniques - a review, Anaesth. Interns. Care 1: 400 (1973)

2. Thomas, E. Bacterial hazards and control in anaesthesia. AORN journal 19: 88 (1974).

3. Walter, Carl. Cross infection and the anaesthesiologist. Anaesth. \& Analg. 35: 631 (1974).

4. Paxdit, S.K., Mehta, S., \& AGahwal, S.C. Risk of cross infection from inhalation anaesthetic equipment. Brit. J. Anaesth. 39: 838 ( 1967).

5. Drydex, G.E. Uncleaned anaesthesia equipment. J.A.M.A. 233: 1297 (1975).

6. Roneris, R.B. Eradication of cross infection from anaesthetic equipment. Anaesth. \& Analg. 49:63(1970).

7. Albrecht, W.H. \& Dhydes, G.E. Five-year experience with the development of an individually clean anaesthesia system. Anaesth. \& Analg. 53: 24 (1974).

8. Parmeey, J.B., Tahir, A.H., Dascomb, H.E., \& ADRIANi, I. Disposable versus reusable breathing circuits; advantages, disadvantages, hazards and bacteriologic studies. Anaesth \& Analg. 51: 888 (1972).

9. Pethick, S.L. (Letters to the editor). Can Anaesth. Soc. J. 22: 115 (1975).

10. JOSEPH, J.M. Disease transmission by inefficiently sanitized anaesthetizing apparatus. J.A.M.A. 149: 1196 (1952).

1.1. Tinve, J.E., Gondon, A.M., Barn, W.H., \& Mackey, W.A. Cross-infection by Pseudomonas aeruginosa as a hazard of intensive surgery. Brit. Med. J. 4: 313 (1967). 
12. Old, J.W., Kisch, A.L., Eberle, B.J., \& Wilson, J.N. Pseudomonas aeruginosa respiratory trict infection acquired from a contaminated anaesthesia machine. Am. Rev. Respir. Dis. 105: 628 (1972).

13. Warnen, P. \& Doherty, J. Disinfection of anaesthetic apparatus. Can. J. Surg. 3; 349 (1960).

14. Lumley, J. Decontamination of anaesthetic equipment and ventilators. Brit. I. Anaesth. 48: $3(1976)$

15. Whitcher, C.E. Dirty equipment - cleaning and sterilization. Audiodigest Anaesthesiology 17: 14 (1975).

16. Craig, D.B., Cowan, S.A., Fonsyth, W., \& Palker, S.E. Disinfection of anilesthesial equipment by a mechanized pasteurization method. Can. Anaes. Soc. J. 22: 219 (1975).

17. Rouerts, R.B. (Editor). Infections and sterilization problems. International Anaestliesiology Clinics 10: 2 (1972).

18. Marx, G.F, Hazards associated with ethylene oxide sterilization. N.Y. State I. Med. 69 : 1319 (1969).

19. Rendell-Baker, L. \& Ronerrs, R.B. Safe use of ethylene oxide sterilization in hospitals. Anaesth. \& Analg. 49: 919 (1970).

20. Lipton, B., Cutierrez, R., Blaugrund, S., Litwak, R., \& Rendell-Bakeh, L. Imidiated PVC plastic and gas sterilization in the production of tracheal stenosis following tracheostomy. Anaesth. \& Analg. 50: 578 (1971).

21. Holley, H.S. \& Gildea, J.E. Vocal cord paralysis after tracheal intubation. J.A.M.A. 215: $281(1971)$.

22. Cuxlmfe, A.C. \& Weslex, F. Hazards from plastics sterilized by ethylene oxide. Brit. Med. J. 2: 575 (1967).

23. Stetson, J.B., Whiprounxe, J.E., \& Eastaran, C. Ethylene oxide degassing of rubber and plastic materials. Anaesthesiology $44: 174$ (1976). 